\title{
ИССЛЕДОВАНИЕ ВЛИЯНИЯ РАЗЛИЧНЫХ ВЫПУСКНЫХ ФОРМ ТЕРМОСТАБИЛИЗАТОРА Н-1 НА ТЕРМООКИСЛИТЕЛЬНУЮ ДЕСТРУКЦИЮ СТАБИЛИЗИРОВАННОГО ПОЛИКАПРОАМИДА
}

O. KIRRET, L. KUTIINA, Maret KRULL, M. SERDJUKOVA, G. VASSILENKO, V. ROZANTSUK, Aili KOGERMAN. TERMOSTABILISAATOR H-1 ERINEVATE TOOSTUSLIKE VORMIDE MOJU STABILISEERITUD POLOKAPROAMIIDI TERMOOKSODEERIVALE LOHUSTUMISELE

O. KIRRET, L. KUTYINA, Maret KRULL, M. SERDYUKOVA, G. VASILENKO, V.ROZHANCHUK, AIII KOGERMAN. INVESTIGATION OF THE EFFECT OF COMMERCIAL TYPES OF THERMOSTABILIZER H-1 ON THE THERMOOXIDATIVE DESTRUCTION OF STABILIZED POLYCAPROAMIDE

В настоящее время для термостабилизации капроновых нитей технического назначения используется термостабилизатор H-1, выпускаемый Рубежанским производственным объединением «Краситель» в виде застывшего плава. Такая выпускная форма термостабилизатора вызывает затруднения при оценке качества поступающего продукта и увеличивает трудоемкость процесса, связанного с измельчением и дозировкой стабилизатора [']. Поэтому были начаты исследования по изысканию новых выпускных форм термостабилизатора Н-1, более удобных для использования в производстве.

Днепропетровским химико-технологическим институтом была разработана новая выпускная форма Н-1 в полиэтиленгликоле (ПЭГ), Рубежанским производственным объединением «Краситель» - выпускная форма Н-1 в капролактаме. Для определения эффективности новых выпускных форм Н-1 интересно было изучить их влияние на термоокислительную деструкцию поликапроамида (ПКА) в сравнении с термостабилизатором в плаве с помощью методов ИК-спектроскопии и ПГХ.

В качестве объектов исследования были применены пленки ПКА, содержавшие до $0,3 \%$ стабилизатора от веса капролактама, в различных выпускных формах. Пленки толщиной $20-25 \mu$ готовили путем высаживания стабилизированного ПКА из растворов в тетрафторпропаноле. Спектры снимали на спектрометре UR-20 и спектрофотометре СФ-4. Степень термоокислительной деструкции оценивалась по концентрации карбонильных групп в полимере на основании интегральной интенсивности полосы поглощения $1713 \mathrm{~cm}^{-1}$ при прогревании исследуемых пленок при температуре $200^{\circ} \mathrm{C}$ в течение от 1 до 20 ч (см. рис. 1). Как видно из представленных данных, накопление СО-групп в пленках с Н-1 при прогревании их в течение 4-6 ч практически одинаково для всех выпускных форм Н-1. При увеличении времени прогрева до 8 ч и выше наблюдается резкое повышение содержания 
Рис. 1. Зависимость относительной интегральной интенсивности полосы поглощения $1713 \mathrm{~cm}^{-1}$ ПКА от продолжительности прогревания при $200^{\circ} \mathrm{C} . K-$ контрольный образец, без стабилизатора; 1 H-1 (ПЭГ); 2 - $\mathrm{H}-1$ (капролактам); 3 - Н-1 (плав); 4 - Н-1 (чистый, в поpошке).

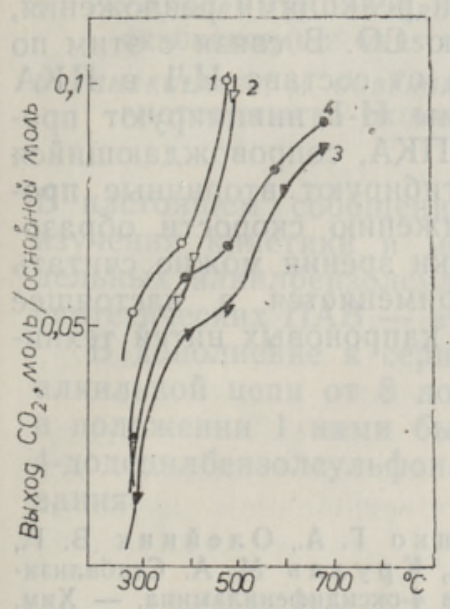

Рис. 2. Влияние температуры пиролиза полимера и состава стабилизатора на выход $\mathrm{CO}_{2}$. 1 - Н-1 (капролактам); 2 $\mathrm{H}-1$ (ПЭГ); 3 - $\mathrm{H}-1$ (плав); 4 - без стабилизатора.
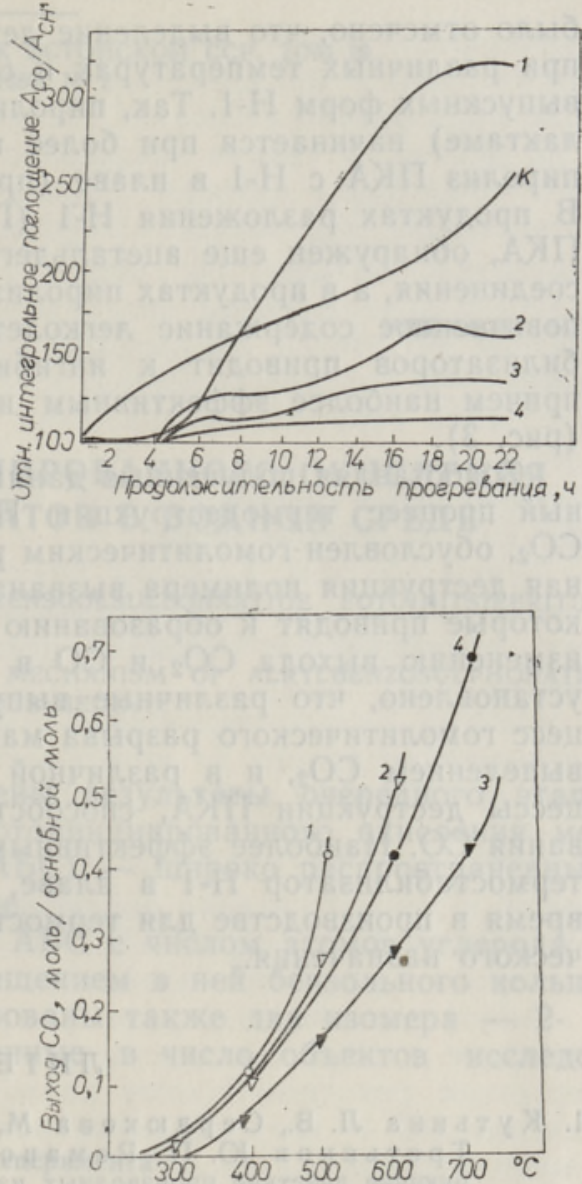

Рис. 3. Влияние температуры пиролиза полимера и состава стабилизатора на выход СО. 1 - $\mathrm{H}-1$ (капролактам); 2 - Н-1 (ПЭГ); 3 - Н-1 (плав); 4 - контрольный, без стабилизатора.

CO-групп, особенно для ПКА, стабилизированного Н-1 (ПЭГ), в меньшей степени для H-1 (в лактаме). Таким образом, эти стабилизаторы тормозят термоокислительную деструкцию только в начальной стадии, и их эффективность снижается при более длительном температурном воздействии.

Для подтверждения данных, полученных методом ИК-спектроскопии, термическое поведение стабилизированного ПКА изучали с помощью ПГХ. Пиролиз исследуемых объектов проводили в реакторе, совмещенном с аналитической частью хроматографа, в атмосфере инертного газа при температуре $200-800^{\circ}$ в течение $\left.12{ }^{2}{ }^{2}{ }^{2}\right]$. Продукты пиролиза в токе инертного газа поступали в разделительную колонку хроматографа, а оттуда в детектор. При этом изучали влияние состава термостабилизатора и температуры пиролиза на выход $\mathrm{CO}_{2}$ и $\mathrm{CO}$.

Результаты анализа (рис. 2 и 3) показали, что с повышением температуры пиролиза выход $\mathrm{CO}_{2}$ и $\mathrm{CO}$ повышается во всех опытах, Однако 
было отмечено, что выделение летучих продуктов пиролиза начинается при различных температурах и состав их не одинаков для различных выпускных форм Н-1. Так, пиролиз ПКА с Н-1 (ПЭГ) и Н-1 (в капролактаме) начинается при более низких температурах (при 250), чем пиролиз ПКА с Н-1 в плаве (при $300^{\circ}$ ), с выделением $\mathrm{CO}_{2}$ (рис. 2). В продуктах разложения Н-1 (ПЭГ), помимо продуктов разложения ПКА, обнаружен еще ацетальдегид и некоторые кислородсодержащие соединения, а в продуктах пиролиза Н-1 (в капролактаме) наблюдалось повышенное содержание легколетучих продуктов. Введение термостабилизаторов приводит к ингибированию процесса образования СО, причем наиболее эффективным ингибитором является H-1 (в плаве) (рис. 3).

Сопоставляя полученные данные, можно предположить, что начальный процесс термодеструкции ПКА, сопровождавшийся выделением $\mathrm{CO}_{2}$, обусловлен гомолитическим разрывом связей $-\mathrm{NH}-\mathrm{CO}-$. Основная деструкция полимера вызвана вторичными реакциями разложения, которые приводят к образованию и выделению СО. В связи с этим по изменению выхода $\mathrm{CO}_{2}$ и $\mathrm{CO}$ в зависимости от состава H-1 в ППКА установлено, что различные выпускные формы $\mathrm{H}-1$ инициируют процесс гомолитического разрыва макромолекул ПКА, сопровождающийся выделением $\mathrm{CO}_{2}$, и в различной степени ингибируют вторичные процессы деструкции ПКА, способствующие снижению скорости образования СО. Наиболее эффективным с этой точки зрения можно считать термостабилизатор Н-1 в плаве, который применяется в настоящее время в производстве для термостабилизации капроновых нитей технического назначения.

\title{
Л И Т Р Р А У Р А
}

1. Кутьина Л. В., Сердюкова М. А., В асиленко Г. А., Олейник В. Г., Т ретьяков Ю. П., Р ом ановская Л. Г., Крулль М. А. Стабилизирующее действие производных из класса эфиров 4-оксидифениламина. - Хим. волокна, 1977 , № 4, с. 33-34.

2. Krull, M., Kogerman, A., Kirret, O., Kutyina, L. Zapolski, D. Pyrolysis gas chromatography of capron (nylon-6) fibre stabilized with ethers of 4-oxydiphenylamine. - J. Chromatogr., 1977, v. 135, p. 212-216.

\author{
Ннститут химии \\ Академии наук Эстонской ССР \\ ВНинв Проект, Киевский филиал
}

Поступила в редакцию 